\title{
An Analysis of Factors Influencing Customer Creditworthiness in the Banking Sector of Kingdom of Bahrain
}

\author{
Maryam Ismail Ebrahim \\ New Accounts Analyst - Risk Department, AMA International University, KINGDOM OF BAHRAIN
}

Corresponding Author: mariam_a.rasool@live.com

\begin{abstract}
This research is based on Bahraini bankers' perception on the factors influencing customer creditworthiness in the banking sector of Kingdom of Bahrain. We consider that the research was done in the Kingdom of Bahrain which has a growing banking industry. To enhance the whole procedure of the creditworthiness, it is vital for an employer to understand the most important factors influencing customer creditworthiness. The purpose of the study was to investigate the factors influencing customers creditworthiness in the banking industry. The creditworthiness can be assessed through qualitative factors, quantitative factors and risk factors. The research was conducted through a survey, using the questionnaire as the research instrument. The respondents of the study are employees of banks across the Kingdom dealing with creditworthiness. The statistical tools used in the study are Multiple Regression Analyses and weighted mean. The researcher has found that there is significant relationship between all three factors and creditworthiness, and they don't equally influence the creditworthiness. The research provides recommendations to banks in assessing the creditworthiness. The researcher recommended that employees must use the most effective methods such as credit scoring to conduct the analysis of creditworthiness in order to make effective decisions. Moreover, the researcher recommended that analysts should take into considerations the most effective factors in the analysis process and they must not neglect other.
\end{abstract}

Keywords-- Creditworthiness, Banking Industry, Qualitative, Quantitative, Risk

\section{INTRODUCTION}

During the most recent decades the globalization of financial markets, the aggressive challenge among firms, financial establishments and associations and the economic changes, social and technological changes, have increased the level of risk as well as the instability in the financial and business environment. The importance of making effective and efficient financial decisions has been the major focus of financial firms, likewise the process of the creditworthiness of the applicants have changed and it expanded its segments to include many levels and department to make an effective and efficient risk wise decisions.
Creditworthiness is how a bank, or a financial institute verifies that you will default on your debt commitments, or that you are so qualified to get new credit. Your creditworthiness is the thing that creditors take a gander at before they affirm any new credit to you. Creditworthiness is dictated by a few elements including your reimbursement history and credit score. Some credit companies consider the client's assets and the measure of liabilities you have when they decide the likelihood of default (dezfouli,2014).

The creditworthiness tells a creditor exactly how reasonable you are for the loan or credit card application you are requesting. The decision the organization makes depends on how you've managed your credit before. To do this, they take a gander at a few unique factors such as qualitative, quantitative and risk. For example; your general credit report, credit score, and installment history. The credit report highlights how much debt the clients convey, high balances, credit facilities customers have, and the outstanding balance of each record. It will also highlight any vital data for the potential loan specialist including whether you've had any past due sums, any defaults, liquidations, as well as collection things. The creditworthiness is estimated by the credit score, which estimates you on a numerical scale dependent on your credit report. A high credit score implies your creditworthiness is high. Alternately, low creditworthiness originates from a lower credit score. Payment history additionally is a major key in deciding the creditworthiness. Banks don't extend credit to somebody whose history exhibits late installments, missed installments, and defaulting contracts (Thomas, 2000).

\section{BACKGROUND}

Lending plays an important role in the economy of Bahrain, therefore financial institutes and banks keeps on upgrading their strategies and polices to come up with the most effectives procedures in assessing the creditworthiness of their clients (Buchari,2014). In order to make efficient decisions when it comes to lending, a bank must identify whether the client is worthy or not, this can be done through identifying the main factors that affects the creditworthiness process and does each factor affect the decision 
(Elkelish,2015). The most commonly used methods in the financial sector to identify the creditworthiness is credit scoring, in which qualitative and quantitative factors are identified along with credit risk associated with each applicant's profile. If the financial analyst ignored one of the factors during the process, he could over value or under value the clients', where a credit facility could be granted to someone unworthy with high risk. In such cases a customer could default the payment and incur losses to the bank (Buchari, 2014).

The objective of this research is to:

1. To know the various factors affecting creditworthiness.

2. To analyze the relationship between qualitative and creditworthiness.

3. To analyze the relationship between quantitative and creditworthiness.

4. To analyze the relationship between credit risk and creditworthiness.

5. To identify the most important factor that influences the creditworthiness.

The researcher's conceptual framework of the study is developed based on the theoretical framework and the statement of problem to be addressed. In this study the independent variables are Quantitative factors, Qualitative factors and risk factors. The dependent factor is creditworthiness.

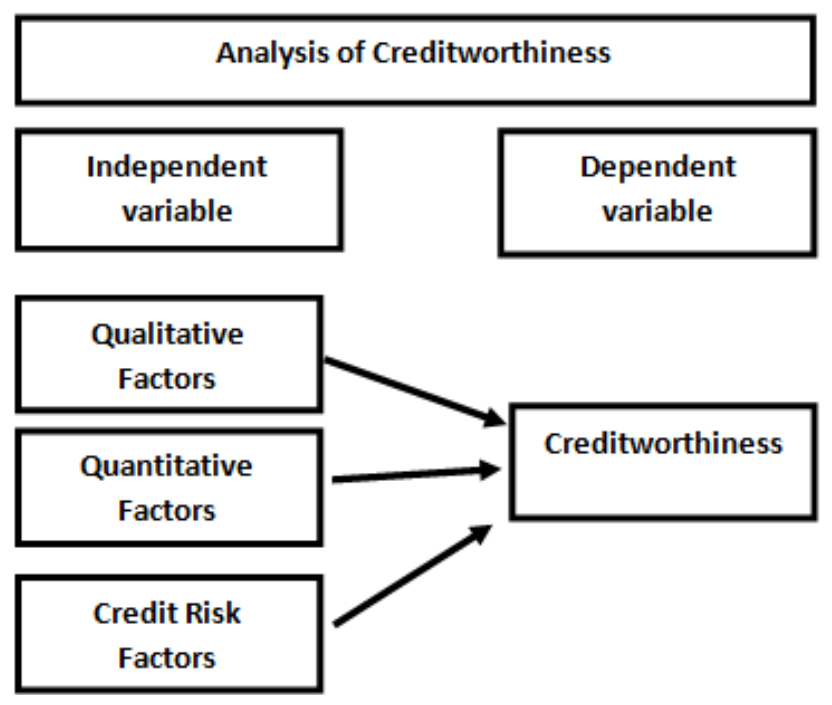

The framework illustrates the basic variables in which the creditworthiness process focuses on, and what each variable will lead to. The process starts by the acquisition of new customer or existing customer by the sales department. Then the customer documentation will be handed to the risk department. The risk department will carry the necessary checks on customers profiles based on qualitative, quantitative methods and credit risk assessment to make an accurate decision. The independent variables which affects the creditworthiness in this research are: qualitative quantitative methods and credit risk. Where in the framework qualitative refers to the quality applicants' profile who are applying for a credit facility. While quantitative is referred to the number of mathematical and statistical mythologies used to do the necessary calculations for the applicants. And finally, risk is the occasion where a customer would default a payment, that's why during the decision-making process, risky profile must be assessed very well, and it must be escalated to higher authorities before granting them any credit facility to manage the uncertainty.

\section{REVIEW OF RELATED LITERATURE AND STUDIES}

Creditworthiness analysis is a major step of the financial decision-making process. Financial decision making includes examining the financial issues that the organization faces and choosing which decision to be taken. The job of financial investigation might be accepted by any manager. Financial knowledge is the most important aspect in creditworthiness analysis, and it is the procedure by which individuals improve their knowledge of factors, administrations, services and ideas so they are enabled to settle on educated decisions, maintain a strategic distance from traps (Cole and Shastry,2008). The authors explained four section model of training in which financial education looks forward to enhancing financial learning on aspects such as creditworthiness, which improves financial practices and decisions which provides favorable outcomes.

Well educated and knowledgeable individuals are substantially more to make good plans regarding wealth. In terms of quantitative analysis, a lot of authors, researchers and scholars concurred that the most ideal approach to deal with the quality, quantity and risk when making a decision in the financial sector is by using the credit scoring model. A study by Thomas et.al., (2017) showed the effects and advantages of credit scoring in evaluating the creditworthiness. As in their book they described credit scoring as the most gainful and effective measurable and operational instrument in the financial segment. The credit scoring aids the decision making process, where it will furnish the bank with procedures on how much credit will be given to the customer, at what cost they will get it and what kind of strategies should be adapted to increase their profit, this model will survey the creditworthiness of the client in the event that the client is valuable or not. Getting a concise examination about the client's creditworthiness will break down the uncertainty related to the decision, as granting an amount of money to the customer or issuing a credit card comes with a great deal of risk weather the customer is going to pay the amount fully successful or he is going to default the payment. 
The authors described two types of credit scoring in the decision-making process, one of them is for new applicants and the other one is for existing customer to give the client higher credit facility, for example, new loan structure or increment in the credit card limit. This sort of procedure is called application scoring. The scoring will be founded on specific characteristics and the gathering of the candidate's information, for example, age, gender, Marital status, salary, Employer details, liabilities, credit bureau reports and their credit history. The authors study focused on how to maximizes the lenders profitability from their customers using the credit scoring for making decisions instead of just focusing on whether the customer will default the payment or not, this way the bank will predict risk as well as maximizing their profit. This study demonstrates how the financial segment benefited from the credit scoring application in their decision-making process, as in the ancient times the banks used to meet their candidate before starting their analysis and with the growing number of applications, they experienced considerable difficulties in handling the applications with the given number of analysts in the risk department. After the presentation of this technique, it helped in making the lending decision very quickly and easy.

For instance, in the case of credit cards, it would give the assigned limit to the applicant based on his characteristics and it will give the final decision whether to approve or reject the application, moreover the management can increase and decrease the limit based on the customers worthiness.

Another writer Abdelmoula(2015) agreed to a similar idea about the credit scoring in her article about "Bank credit risk analysis". commercial banks that give customer loans need steady models that can accurately identify and anticipate defaults. Concentrating that it is one of the main procedures which any bank needs to manage, in the current focused and violent business condition, is to lessen its credit risk. She stated that they utilize scoring strategies to evaluate the credit worthiness of a credit candidate. Indeed, the quantitative technique known as credit scoring has been created for the credit appraisal issue. Credit scoring is essentially an application of classification methods, which order borrower into various risk segments. The target of Scoring strategies is to foresee the likelihood that a borrower or counterparty will default. In credit risk assessment, Credit scoring is a key strategy, that assist financial organization to settle on a decision regardless of whether to give credit to client or not. As indicated, "a typical methodology of credit scoring is to apply a grouping procedure on information of old clients (both great credit clients and delinquent clients) to discover a connection between the clients attributes and potential inability to meet their obligation. Organizations use credit scoring procedures (using data from the customers past credit

history and current financial conditions) to figure out which candidates will pay back their liabilities". A precise classifier is important to separate between new eligible potential client and bad candidate.

The authors Abdou et al., (2016) wrote about the credit scoring and Predicting creditworthiness in retail banking with limited scoring data, agreeing that credit scoring is the best quantitative method used in the creditworthiness. Where the authors stated that the capacity of measurable credit scoring frameworks to improve decision making and time efficiencies in the financial sectors has been the focus of researchers and analysts.

\section{RESEARCH DESIGN}

The research design is a mix of Inferential and analytic, in which it uses random sample taken from the population. The respondent of the study refers to the employees of several banks in Bahrain which participated in the survey and they have respondent to the questionnaire. The population of this survey are employees of banks who are assessing creditworthiness. Due to confidentiality reasons, the banks were not willing to provide the number of employees assessing the creditworthiness of customers. Therefore, the population cannot be defined. The study used population proportion formula for calculating the sample size.

The research technique used in this study is the questionnaire that was given to a group of banks' employees (managers, and senior employees) to assess their insight on the creditworthiness process subject. In this research the sampling frame contained the employee data of selected banks. The data base contained information such as such as: gender, age group, and education level. Moreover, the researcher used simple random sampling, which is the basic sampling technique where the researcher selects a group of people (a sample) for study from a larger group (a population). Each individual is chosen entirely by chance and each member of the population has an equal chance of being included in the sample (Larson,2014).

The sample was randomly selected, and the size of this study is calculated based on Cochran formula:

\section{Equation 1:}

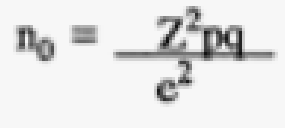

In this research the 97 respondents were randomly selected from the banking sector to participate in the survey. In this paper, the researcher adopted questionnaire as the research instrument. The researcher did face validity for the questionnaire by three managers. The questionnaire the researcher used for the research is Likert scale named 
after its developer. The Likert scale is one of the most widely used itemized scales. The endpoints of a Likert scale are typically "Strongly Disagree", "Disagree", "Neutral", "Agree" and "Strongly Agree."

Research Instruments adopted (Reliable/ Validity/ Creditability of the gathered information). If a research has reliable and valid data, the quality of the research will be high and the result will be meaningful (Yin, 1989). The consistency of the data determines its reliability based on the right measurement tool for the information. Data can be called reliable when it is consistent and dependable, this can be achieved by having the right measurement tool for the information (Lincoln and Guba, 1985). On the other hand, the interpretation does not have much importance because it should consist of qualitative approach that extracts live data (Collis and Hussey, 2009).

This research utilizes a number of Data Gathering Procedures. For collecting primary data, it utilized quantitative research method, namely questionnaire survey, which is discussed in detail in the following chapter. However, in analyzing the data collected through questionnaire, interpretive and statistical analysis is performed respectively using multiple regression analysis.

\section{ANALYSIS AND INTERPRETATIONS}

This section contains the analysis of the data in regards of the questionnaire and questionnaire participants. The analysis will be based on 97 respondents of the banking sector in Bahrain. The undertaken analysis divided the respondents into gender, age group, employment and education level.

The analysis for the demographic pattern of respondents showed that the Majority of respondents were from the age group of 31-35, which indicates that the respondents have gained enough experience and knowledge in the Banking and financial sector to give their reviews about the analysis. Meanwhile, most of the participants were females as the percentage of the female respondents scored $66 \%$, while the men's participant percentage was $34 \%$.In the survey, $93 \%$ of the respondents are holding a bachelor's degree, 5\% are master's holders. Moreover, $1 \%$ of respondents has a $\mathrm{PhD}$ as well as High school diploma. This Survey was specially made to target employees of the Banking sector. The data is interpreted to explain the relationship between the factors Qualitative, Quantitative and risk is to identify the most important factor that influences the creditworthiness.
Next, a correlation and regression analysis were undertaken to measure the relationship between the Qualitative, Quantitative and Risk and their effect on creditworthiness. The independent variables are Qualitative (QN), Quantitative (QL) and Risk (RK) and the dependent variable is Credit Worthiness $(\mathrm{CW})$.

The model of the regression would be in the form of:

Creditworthiness $(\mathrm{CW})=\alpha+\beta$ Qualitative $(\mathrm{QL})+\beta$ Quantitative (QN) $+\beta$ Risk (RK)

The values for $\mathrm{R}$, and $\mathrm{R}$ squared were calculated. The estimated R-value (correlation coefficient) is 0.507. The R2 value for the estimated equation is 0.257 , which is significant at 1 per cent level of probability. It shows that 25.7 per cent of the variation in the creditworthiness is explained by the independent variables identified by the researcher.

Joël Bessis (2017) wrote about the creditworthiness through appraisal of the credit quality of the borrowers utilized in banking in that they incorporate judgmental segments along with qualitative and quantitative data. Qualitative components characterized by the author for example, strength or weakness of entity. The writer expressed that a combination of qualitative and quantitative analysis along with risk analysis is utilized for evaluating the credit standing of borrowers, alongside a professional help who are expert in credit decisions.

The ANOVA values were also calculated. The sum of squares, degrees of freedom, and mean square are displayed for two sources of variation, regression and residual. The output for Regression displays information about the variation accounted for by your model. The output for Residual displays information about the variation that is not accounted for by your model. And the output for Total is the sum of the information for Regression and Residual. A model with a large regression sum of squares in comparison to the residual sum of squares indicates that the model accounts for most of variation in the dependent variable. Very high residual sum of squares indicate that the model fails to explain a lot of the variation in the dependent variable, and you may want to look for additional factors that help account for a higher proportion of the variation in the dependent variable. If the significance value of the $\mathrm{F}$ statistic is small (smaller than say 0.05) then the independent variables do a good job explaining the variation in the dependent variable. If the significance value of $\mathrm{F}$ is larger than say 0.05 then the independent variables do not explain the variation in the dependent variable.

Here the significant value is .000 It indicates that the independent variables do a good job explaining the variation in opinion of overall library sources. 


\begin{tabular}{lll}
\multicolumn{1}{c}{ Regression coefficients } & & \\
\hline Identified Latent Factors & Coefficients & Sig. \\
\hline Constant & 2.188 & 0.201 \\
Qualitative & 0.134 & $0.0252^{*}$ \\
Quantitative & 0.966 & 0.000 \\
Risk & -0.510 & $0.0105^{* *}$ \\
\hline
\end{tabular}

*Significant at 5\% level ** Significant at $1 \%$ level

The above table shows the estimated regression coefficients of the regression model fitted. Here the estimated model is:

$\mathrm{CW}=2.188+0.134 \mathrm{QL}+0.966 \mathrm{QN}-0.510 \mathrm{RK}$

Where:

$\mathrm{CW}=$ Creditworthiness

$\mathrm{QL}=$ Qualitative

$\mathrm{QN}=$ Quantitative

$\mathrm{RK}=$ Risk

The regression results indicate that all the independent factors positively influence the creditworthiness except for risk which has a negative impact on the creditworthiness. This is evident from the positive signs of the estimated coefficients of the independent factors. This means that if any of the factors increase, the creditworthiness of an applicant will also increase. The regression shows that among all the factors influencing the creditworthiness, the quantitative variable (0.966) have the highest beta value indicating that it is the most influencing factor which influence the creditworthiness. Also, this factor is significant at one percent level. The results of this research show that the factor that affects creditworthiness the most is Quantitative factor and has an influence on the decisions to be taken, whether to grant a credit facility to the applicant or not.

The above result indicates that $\mathrm{Ho} 1, \mathrm{Ho} 2, \mathrm{Ho} 3$ and Ho4 are rejected:

Ho1: there is no significant relationship between qualitative factors and creditworthiness.

Ho2: there is no significant relationship between quantitative factors and creditworthiness.

Ho3: there is no significant relationship between credit risk factors and creditworthiness.

Ho4: all factors equally influence the creditworthiness

This means that there is relationship between qualitative, quantitative, risk and creditworthiness. Also, it is evident that Quantitative (.966) is the most important factor that influence the creditworthiness.

The study aimed to identify the factors affecting the creditworthiness. Where the researcher has identified three independent factors that affect the creditworthiness. Those factors are Qualitative factors, Quantitative factors and Risk. Moreover, this study aimed to analyze the relationship between these independent variables and the creditworthiness and to identify the most important factor. The research findings indicated that there is relationship between each independent variable and creditworthiness. The treatment of data revealed that Quantitative factor has a beta of 0.966 which is the highest factor in influencing the dependent variable, therefore it is considered to be the most important factor influencing creditworthiness. Banks should focus more on quantitative variable by providing enough methods to the analysts to carry out their jobs and to use the credit scoring in the analysis of creditworthiness. Also, they should not neglect other factors such as qualitative and risk as they also have an effect on the creditworthiness.

To conclude, the results indicated that all 4 Hypothesis (H01), (Ho2), (Ho3) and (Ho4) are rejected by the researcher. The researcher has proven that there is relationship between all independent variables and dependent variable and that they don't equally influence the dependent variable.

\section{RECOMMENDATIONS, CONCLUSION AND FUTURE STUDIES}

Based on the questionnaire survey and the findings, the following recommendations are proposed:

Banks should follow the most effective methods such as credit scoring to conduct the analysis of creditworthiness in order to make effective decisions. Analysts should take into considerations the most effective factors in the analysis process and they must not neglect other factors.

Quantitative factors have high impact on the creditworthiness; therefore, it is mandatory to ask to the applicant for source of income and current liabilities to make sure that the customers have sufficient funds to cover the credit granted. Using this survey of the analysis of Creditworthiness banks can verify risk associated with each profile and therefore they will be able to minimize losses.

For researcher that would like to investigate in the same topic, the researcher recommends more variables to be added in the study to investigate if there are more variables that influences the creditworthiness. Also, a larger sample size can be increased by adding financial institutes 
and insurance companies. Moreover, the study can be conducted on the GCC country to test the similarity of the process used in the region.

\section{REFERENCES}

[1] Abdelmoula, A. K. (2015). Bank credit risk analysis with k-nearestneighbor classifier: Case of Tunisian banks. Institut des Hautes Etudes Commerciales de Carthage, 14(1), 79-106.

[2] Abdou, H. A., Tsafack , M. D., Ntim, C. G., \& Baker, R. D. (2016). Predicting creditworthiness in retail banking with limited scoring data. Journal Elsevier, 103, 89-103.

[3] Adeusi, S. O., Akeke, N., Adebis, O. S., \& Oladunjoye, O. (2014). Risk management and financial performance of banks in Nigeria. IOSR Journal of Business and Management, 14(6), 52-56.

[4] Almansour, B. Y. (2015). Empirical model for predicting financial failure. American Journal of Economics, Finance and Management, 1(3), 113-122.

[5] Aven, T. (2016). Risk assessment and risk management. European Journal of Operational Research, 253, 1-13.

[6] Brown, K. \& Moles, P. (2014). Credit risk management. ( $1^{\text {st }}$ ed.). Edinburgh: Heriot-Watt University.

[7] Buchari, I., Rafiki, A., \& Al Qassab, M. A. (2014). The employees' awareness and attitudes towards islamic banking products: A survey of Islamic banks in Bahrain. World Applied Sciences Journal, 32(3), 436-443.

[8] Burakov, D. V., \& Burakov, D. V. (2014). Do Methods of Estimantion Affect Credit Risk Oscillations? Mediterranean Journal of Social Sciences, 5(20), 114-120.

[9] Neda Abdulkarim Albaqqali \& Jayendira Sankar. (2019). Empowerment and its relation with the job performance among the bank employees in the Kingdom of Bahrain. International Journal of Engineering and Management Research, 9(1), 27-31.

[10] Cole, S. \& Shastry, G. K. (2008). If you are so smart, why arent you rich? The effects of education, financial literacy and cognitive ability on financial market participation. Available at:

http://www.people.hbs.edu/scole/webfiles/cole-shastrysmarts\%20HBS\%20working\%20paper.pdf.

[11] Dezfouli, M. H., Hasanzadeh, A., \& Shahchera, M. (2014). Assessing the profitability of the iranian banking system's non-linear relationship with liquidity risk . Kuwait Chapter of Arabian Journal of Business and Management Review, 3(9), 226-235.
[12] Doležal, J., Šnajdr, J., Belás, J., \& Vincúrová, Z. (2015). Model of the loan process in the context of unrealized income. Journal of International Studies, 8(1), 91-106.

[13] Elkelish, W. W., Miniaoui, H., \& Al Tamimi, H. A. (2016). Financial risk and islamic banks' Performance in the gulf cooperation council countries. The International Journal of Business and Finance Research, 9(5), 103-112.

[14] Ghenimi, A., Chaibi, H., \& Omri , M. A. (2017). The effects of liquidity risk and credit risk on bank stability. Borsa Istanbul Review, 17(4), 238-248.

[15] Jagtiani, J. \& Lemieux, C. (2017). Fintech lending: financial inclusion,risk pricing, and alternative information. Chicago: Federal Reserve Bank of Philadelphia.

[16] Khaliq, A., Hussein, B., Altarturi, M., Thaker, H. M., Yousuf, M. H., \& Nahar, N. (2014, January). Identifying financial distress firms. International Journal of Economics, Finance and Management, 3(3), 141-150.

[17] Roozmehr Saf \& Zhangxi Lin. (2014). Using nonfinancial data to assess the creditworthiness of business in online trade. Available at:

https://pdfs.semanticscholar.org/512a/1bd31faf7a21f3f260d c7002239b21eb303c.pdf..

[18] McNeil, A. J., Frey, R., \& Embrechts, P. (2015). Quantitative risk management. ( $1^{\text {st }}$ ed.). London: Princton University.

[19] Guidelines on Credit Risk Mangement. (2014). Credit approval process and credit risk management. ( $1^{\text {st }}$ ed.). Vienna, Austria: OENB.

[20] Nikolaidoua, E., \& Vogiazas, S. (2017). Credit risk determinants in Sub-Saharan banking systems. Elsevier, 7, 52-63.

[21] Puri, T., Sibdari, S., \& Zhang, X. (2016). Improving credit scoring quality through virtual organization. Available at: http://www.bapress.ca/jcm/jcm-article/19290136-2017-01-25-14.pdf.

[22] Sudhakar , M., \& Reddy, C. V. (2016). Two step credit risk assesment model for retail bank loan applications using decision tree data mining technique. International Journal of Advanced Research in Computer Engineering \& Technology, 5(3), 705-718.

[23] Thomas, L., Crook, J., \& Edelman, D. (2017). Credit scoring and its applications ( $2^{\text {nd }}$ ed.). London: SIAM.

[24] Zhanga, Y., Jiaa, H., Diaoa, Y., Haia, M., \& Lia, H. (2016). Research on credit Scoring by fusing social media information. Elsevier, 91, 168-174. 